\title{
REFLEXÕES SOBRE A TRAMA GEOGRÁFICA ENTRE ESPAÇO E RELIGIÃO
}

\author{
Roseane Richele de Medeiros ${ }^{1}$ \\ Diego Salomão Candido de Oliveira Salvador ${ }^{2}$
}

\begin{abstract}
RESUMO
A geografia tem sido renovada ao longo da história do seu pensamento, mirando a compreensão ou a interpretação da complexa relação entre o homem e o meio. Consideramos que a geografia possibilita a elaboração e a discussão de diversos saberes, todos com a característica comum da sua implicação no entendimento da produção ou da organização do espaço geográfico. A religião é um saber que pode ser discutido na ótica geográfica, não obstante ser negligenciado pela maior parte dos geógrafos. Na história do pensamento geográfico houve certa resistência por parte de muitos estudiosos de se fazer uma abordagem geográfica da religião. Nos dias de hoje, o diálogo entre geografia e religião ocorre por meio de estudos voltados para os fenômenos religiosos na dinâmica espacial, os lugares enquanto espaços sagrados e profanos, as paisagens sagradas e as territorialidades, assim como os territórios conformados pelas religiões. Destarte, a partir da realização de pesquisa bibliográfica sobre espaço e religião, feita em acervos virtuais de bibliotecas universitárias e de periódicos científicos, objetivamos, neste trabalho, refletir sobre o saber religião em geografia, ressaltando-se que a espacialidade sagrada e profana adquire formas e significados próprios que estão expressos no espaço - implícita e explicitamente. Tal fato sublinha a forte ligação entre o homem e o seu espaço.
\end{abstract}

Palavras-chave: geografia; espaço; religião.

\section{REFLECTIONS ON THE RELATIONSHIP GEOGRAPHIC BETWEEN SPACE AND RELIGION}

\section{ABSTRACT}

Geography has been renewed throughout the history of his thinking, aiming at understanding or interpreting the complex relationship between man and the environment. We believe that Geography enables the elaboration and discussion of diverse knowledge, all with the common characteristic of its implication in the understanding of the production or organization of the geographical space. Religion is a knowledge that can be discussed from a geographic perspective, despite being neglected by most geographers. In the history of geographic thought there has been some resistance on the part of many scholars to take a geographical approach to religion. Nowadays, the dialogue between Geography and religion occurs through studies focused on religious phenomena in spatial dynamics, places as sacred and profane spaces, sacred landscapes and territorialities, as well as territories formed by religions. Thus, based on bibliographic research on space and religion, carried out in virtual collections of university libraries and scientific journals, we aim in this work to reflect on the knowledge of religion in Geography, emphasizing that sacred and profane spatiality acquire their own forms and meanings that they are expressed in space - implicitly and explicitly. This fact underlines the strong connection between man and his space.

Keywords: geography; space; religion.

RECEBIDO EM: $13 / 5 / 2020$

ACEITO EM: $21 / 9 / 2020$

${ }^{1}$ Universidade Federal do Rio Grande do Norte (UFRN). http://lattes.cnpq.br/8558164005011374. https://orcid.org/0000-0001-6556-3953

2 Autor correspondente. Universidade Federal do Rio Grande do Norte (UFRN) - Centro de Ensino Superior do Seridó. Rua Joaquim Gregório Penedo. Caicó/RN, Brasil. CEP 59300-000. http://lattes.cnpq.br/5656990960651016. https://orcid.org/0000-0001-5119-1888. diegosalomao84@hotmail.com 


\section{INTRODUÇÃO}

A geografia tem sido renovada ao longo da história do seu pensamento, mirando a compreensão da complexa relação entre o homem e o meio. A nosso ver, a geografia possibilita a elaboração e a discussão de diversos saberes, com o objetivo macro do entendimento da produção ou da organização do espaço geográfico.

A religião é um saber que pode ser discutido na ótica geográfica, não obstante ser negligenciado pela maior parte dos geógrafos. Na história do pensamento geográfico houve certa resistência por parte de muitos estudiosos de se fazer uma abordagem geográfica da religião. Isso ocorreu, em um primeiro momento, pelo fato de a geografia ter sido fundada e desenvolvida de modo clássico - da primeira metade do século 19 até a primeira metade do século 20 - conforme pensamentos e práticas positivistas, por meio de estudos naturalistas e empíricos que relegavam a segundo plano o fator social no entendimento da dinâmica do espaço. Em outras palavras, a relação entre homem e meio era estudada com o privilégio da ação da natureza sobre o homem e a negligência, muitas vezes, do papel ativo que os homens podem exercer no processo de transformação da natureza. Foi, entretanto, no seio do positivismo que surgiram as primeiras tentativas de se aproximar a geografia e a religião por intermédio da "mera classificação dos tipos de efeitos que as religiões tinham sobre a paisagem" (ROSENDAHL, 1996, p. 20).

Outra corrente do pensamento geográfico que vem deixando de lado a abordagem do saber religião é a Geografia Crítica, cujo desenvolvimento ocorre desde a segunda metade do século 20. Embasados no materialismo histórico-dialético, os estudos dessa corrente vêm negligenciando as questões religiosas que caracterizam a produção do espaço, apesar de uma das marcas da Geografia Crítica ser a contestação da neutralidade científica que fora atribuída às questões sociais na perspectiva neopositivista do pensamento geográfico. Segundo Rosendahl (1996), a marginalização das questões religiosas pelos geógrafos críticos explica-se pelo fato de estes privilegiarem o caráter materialista do espaço, negligenciando outros aspectos que também caracterizam a totalidade da dinâmica do espaço, como as imaterialidades que influenciam na produção e na compreensão das materialidades.

De modo concomitante à corrente crítica, entretanto, vem sendo colocado em baila o movimento humanista em geografia, destacando-se a interpretação do espaço geográfico pela relevância do homem, dos seus signos e significados, valores e propósitos, fazendo com que sejam considerados diferentes modos de observação, valorização dos sentimentos, das experiências, dos valores e das atitudes no processo em que o homem e/ou a sociedade produz e significa o espaço geográfico. É sobretudo no contexto da corrente da Geografia Humanística que vêm sendo realizados estudos acerca da religião, fato que traz à tona o campo da Geografia da religião, no qual se interpreta o espaço geográfico considerando-se saberes e práticas de religiões.

Sendo assim, nos dias de hoje o diálogo entre geografia e religião ocorre por meio de estudos voltados para os fenômenos religiosos na dinâmica espacial, os lugares enquanto espaços sagrados e profanos, as paisagens sagradas e as territorialidades, assim como os territórios conformados pelas religiões. 
A partir da realização de pesquisa bibliográfica sobre espaço e religião, realizada em acervos virtuais de bibliotecas universitárias e de periódicos científicos, objetivamos, neste trabalho, refletir sobre o saber religião em geografia, ressaltando-se que a espacialidade sagrada e profana adquire formas e significados próprios que estão expressos no espaço - implícita e explicitamente. Tal fato sublinha a forte ligação entre o homem e o seu espaço.

\section{ESPAÇO E RELIGIÃO NA TRAMA GEOGRÁFICA}

As relações entre geografia e religião são evidentes, uma vez que as dinâmicas espaciais e religiosas se entremeiam por intermédio de ações humanas. Como afirma Rosendahl (1996), são duas práticas sociais: enquanto a religião dita algumas normas para o relacionamento do homem com o espaço, a geografia destaca diferentes maneiras de os homens agirem sobre o espaço e de serem condicionados pelas atuais configurações espaciais, havendo, inclusive, modos estratégicos de operar no/do espaço. Dessa maneira, a religião e a geografia têm relações que são sociais, políticas, culturais e econômicas, apresentando-se, então, como formas de conhecimento inerentes à vida do homem e que circundam suas várias dimensões.

Apesar de a religião ser tema ou tópico de pesquisa em diversas ciências/disciplinas, o estudo geográfico da religião diferencia-se daqueles realizados pela Antropologia e pela Sociologia, por exemplo, tendo-se em vista o fato de, na geografia, o fenômeno religioso ser compreendido por meio da produção do espaço.

Atualmente, na geografia brasileira, temos dois grandes vieses por intermédio dos quais a discussão sobre espaço e religião é realizada: um que aborda o fenômeno religioso por meio de dimensões concretas, com foco sobre a temática das espacialidades da cultura religiosa, tendo como principais temas espaço e lugar sagrado ${ }^{3}$, território e territorialidades religiosas, centros de convergência e irradiação ${ }^{4}$ e difusão e área de abrangência da experiência da fé no tempo e no espaço em que ela ocorre - neste destaca-se a obra de Zeny Rosendahl; o outro viés aborda questões mais subjetivas, com a realização de estudos conforme os princípios da fenomenologia, interpretando-se o espaço por meio da ação do fiel, sublinhando-se as representações, percepções e simbolismos em relação ao fenômeno religioso. Tais questões marcam, sobremaneira, a obra de Sylvio Fausto Gil Filho.

De acordo com Kong (1990), os estudos relacionando espaço e religião começaram a ser desenvolvidos na Antiguidade - de 4.000 a.C. (invenção da escrita) a 476 d.C. (queda do Império Romano), com pensadores gregos - como Anaximandro, o primeiro a fazer um mapa grego destacando o mundo como palco de manifestações religiosas, com a crença de que existiria uma relação entre o visível e o invisível.

\footnotetext{
Segundo Rosendahl (1997), lugares sagrados são espaços dotados de simbolismo religioso, ou seja, espaços vividos por meio da experiência da fé.

4 Os centros de convergência e irradiação caracterizam-se pelos fluxos regulares (peregrinação) a lugares sagrados, com intrínseca relação entre espaço e tempo e a propagação de determinados símbolos e simbologias a diferentes culturas (ROSENDAHL, 1997).
} 
Neste período existia muito mais uma geografia religiosa do que uma Geografia da religião, pelo fato de que alguns pensadores gregos entendiam o mundo por meio da religião, com a incorporação de ideais religiosos para observar o mundo. Com esse entendimento, Kong (1990, p. 356) sublinha que "tais preocupações ligando a geografia e a cosmologia na mente da pessoa religiosa estão no coração da geografia primitiva, e nesse sentido, uma geografia que incorporou ideias religiosas era evidente desde os primeiros tempos".

Na Idade Média - de 476 (queda do Império Romano) a 1453 (tomada de Constantinopla) - o pensamento ocidental foi fortemente influenciado pelos ideais cristãos, relacionando-se, desse modo, as observações e descrições acerca do espaço com o conhecimento religioso. Tal relação era produzida por teólogos católicos e protestantes que pautavam as abordagens geográficas conforme os princípios e a dinâmica do pensamento teológico.

De acordo com Park (1994), entre os séculos 16 e 17, época por ele entendida como a da transição da Idade Média para a Moderna - de 1453 (tomada de Constantinopla) a 1789 (Revolução Francesa) - foram produzidos muitos trabalhos conectando geografia e religião, fato que o leva a denominar essa era de Golden Age (Era Dourada) e a asseverar que tais trabalhos contribuíram para o desenvolvimento do que viria a ser na Contemporaneidade - de 1789 (Revolução Francesa) até os dias atuais - a então Geografia da religião.

Dessa maneira, por diversos motivos, nessa era - a da transição entre a Idade Média e a Moderna - se fazia uma geografia com fins religiosos. Era notável a busca de relacionar-se características do espaço com temas bíblicos, o que legitimava a religião cristã como dominante. Büttner (1979) salienta, contudo, que as ações desse período trouxeram à tona, sobretudo, averiguações empíricas que foram fundamentais para a organização e o desenvolvimento da Geografia da religião.

Na Idade Moderna, as investigações teológicas foram substituídas por uma Geografia eclesiástica, buscando-se cartografar os espaços religiosos no mundo, para, assim, entender as suas organizações e descrever as suas conexões, inclusive entre religiões diferentes. Desse modo, de acordo com Park (2004), tinha-se o objetivo de se apreender a dinâmica espacial das religiões com a finalidade de fundamentar as ações cristãs pelo mundo.

Simultaneamente à Geografia eclesiástica, foi desenvolvida a Geografia histórica dos tempos bíblicos ou Geografia bíblica, para identificar regiões ou lugares a que a bíblia faz referência e, assim, reafirmar o poder e a influência do Cristianismo. Essa perspectiva de investigação atualmente ainda é desenvolvida e apreciada por vários estudiosos, como Ronis (1994), Money (2002) e Andrade (2006).

No século 17 ganhou força a abordagem conhecida como físico-teológica, que vinculava o pensamento religioso às análises geográficas. Tal abordagem já tinha sido ensaiada, na Idade Média, para relacionar fenômenos ambientais à manifestação divina. Essa linha de pensamento influenciou um dos fundadores da ciência geográfica, Carl Ritter (1779-1859), cujo pensamento destacava a natureza como criação divina e, as- 
sim, os fenômenos naturais como determinantes às ações e relações humanas. Usarski (2007) afirma que, nos séculos 18 e 19, colocou-se em baila a tendência proto-determinista, que sublinhava a capacidade do ambiente em determinar certas religiões.

Apesar de alguns estudiosos, como Büttner (1987) e Park (1994), afirmarem que o termo Geografia da religião foi empregado pela primeira vez pelo geógrafo Gottlieb Kasche, em seu livro Ideias sobre a Geografia religiosa (1795), foi apenas no século 20 que a Geografia da religião ganhou realce, sendo apresentada como abordagem da Geografia Humana, na qual se destaca a religião como produto da prática humana e resultado material - expresso na paisagem - da cultura religiosa (GIL FILHO, 2007).

Destarte, o estudo da relação entre fenômeno religioso e espaço geográfico será potencializado com a abordagem proposta por Paul Fickeler ([1947] 2008, p. 8), em Questões fundamentais na Geografia da religião, na qual o autor propõe uma análise geográfica da religião:

se toda religião possui um lado que aborda a conduta pessoal (ético) e um lado que trata da adoração (cerimonial) - um aspecto interno e um externo, que podem ser contrastados, segundo Kant, como a Igreja visível e a Igreja invisível - então a geografia da religião trata acima de tudo da religião cerimonial, devendo lidar com as ideias cerimoniais de mais importante expressão geográfica.

Conforme enfatiza o autor, a relação do fenômeno religioso com a geografia se estabelece pelo espaço, com as marcas das cerimônias religiosas visivelmente percebidas e/ou manifestadas em uma cultura material religiosa. Nesse sentido, em 1948, o geógrafo francês Pierre Deffontaines publicou o livro Géographie et religions, tratando da grande influência que a cultura religiosa pode proporcionar na paisagem, por meio de marcas concretas, como cemitérios e igrejas, que evidenciam relações culturais em determinados contextos geográficos. Acerca dessa obra, Paul Claval (1997, p. 91) expõe:

Pierre Deffontaines aborda a geografia religiosa através das marcas que esta imprime nas paisagens (igrejas, mesquitas, santuários, templos, cruz, etc.) pelos obstáculos que ela impõe a certos gêneros de vida (obrigação do jejum na sexta-feira, interdição do álcool e do consumo de carne de porco, por exemplo), e pelos gêneros de vida que ela faz nascer (o dos padres ou dos monges). A religião não é nunca tratada nela mesma.

No ano de 1967 David Sopher - outro importante estudioso da Geografia da religião - defendeu, no livro Geography of religions, que não se deve estudar a religião por ela mesma, tampouco cabe à geografia a experiência religiosa pessoal. Assim, asseverou que a religião deve ser estudada em geografia como um sistema - que é moldado culturalmente - e como um comportamento institucionalizado.

As abordagens geográficas da religião, propostas por Fickeler ([1947] 2008), Deffontaines (1948) e Sopher (1967), são consideradas as mais contundentes da ciência geográfica durante a primeira metade do século 20 e a transição para a segunda metade desse século. Tais abordagens sublinham a importância do caráter visível da paisagem no que se refere ao fenômeno religioso, destacando-se a descrição de manifestações, ritos e práticas religiosas em determinados lugares. Do mesmo modo, esses autores de- 
fendiam que não seria pertinente estudar em geografia o caráter teológico-filosófico da religião - a religião por ela mesma -, pois essa perspectiva não daria conta da complexidade da análise do referido saber por meio da produção do espaço.

Na segunda metade do século 20 , sobretudo na década de 60 até a de 80 , foi trazida à tona uma fenomenologia religiosa na perspectiva da Geografia Humanística. Assim, geógrafos preocuparam-se com a natureza religiosa de modo existencialista (BUTTIMER, 1976) ou essencialista (TUAN, 1982). De acordo com Usarski (2007), aliadas a essa tendência fenomenológica, porém com menor destaque, foram desenvolvidas também a geoteologia e a Geografia Mítica ${ }^{5}$, com atenção para conceitos espaciais por meio de doutrinas específicas, mas com pouca intensidade de propagação dos resultados dos estudos realizados.

Assim, não obstante o estudo do fenômeno religioso em geografia ter sido negligenciado pelos horizontes (neo)positivista e crítico dessa ciência, a corrente da Geografia Humanista propõe interpretar o espaço geográfico abrangendo formas e conteúdos decorrentes de representações, manifestações e significações da cultura humana, dando realce ao entendimento do fenômeno religioso por meio da interpretação da forma-conteúdo do espaço.

No contexto da Geografia Humanista, dois movimentos epistemológicos mostraram-se importantes para a compreensão da dimensão subjetiva e do cotidiano humano e social na (re)produção do espaço: a Virada Cultural e a Virada Linguística.

A Virada Cultural ou Cutural Turn - como é mais conhecida - foi um movimento científico cuja intensidade de ocorrência remete às décadas de 60 e 70 do século 20 , tendo sido disseminado nas ciências sociais de maneira ampla. Como característica principal, o movimento coloca a cultura como fator importante, senão o principal, dos fenômenos sociais, atribuindo à instância cultural a mesma importância da política e da economia no processo de (re)produção do espaço.

Quanto à Virada Linguística ${ }^{6}$, foi movimento desenvolvido nos anos 1970, que deixou sua marca em duas correntes da renovação da geografia: a Humanista e a Crítica. Nessa perspectiva, obras literárias passaram a ser fonte para investigações geográficas, impulsionando, assim, os estudos do saber religião no que se refere à dinâmica do espaço - de maneira efetiva e não mais subalterna.

Sendo assim, desde a década de 90 do século 20 vem ocorrendo, de modo substancial, a retomada dos estudos da religião em geografia. Na escala internacional, destacam-se as discussões realizadas por Chris Park (1994, 2004), Roger W. Stump (2000) e Lily Kong $(1990,2010)$.

Consoante Park (2004), hoje há duas formas de se estudar religião em Geografia: Geografia religiosa e Geografia da religião. A primeira diz respeito ao papel teológico e cosmológico da religião no entendimento do espaço. A segunda não estuda a

\footnotetext{
Segundo Usarski (2007), a geoteologia ou geografia mítica corresponde a discursos de conceitos elaborados a partir de ideias e pensamentos geográficos oriundos de determinadas tradições religiosas.

6 De acordo com Stadelbauer (2009), a Virada Linguística constituiu-se em um destaque dado à linguagem nas produções humanas, posto que por ela se manifestariam as representações de uma dada cultura. Com isso, os sentidos dos textos e dos espaços começaram a ser fontes de investigações geográficas.
} 
religião em si mesma, mas as diversas maneiras como ela se manifesta por meio da instituição humana, atentando-se, desse modo, para os seus impactos sociais, culturais e ambientais.

Stump (2000) faz uma constatação relevante ao observar que, desde os trabaIhos de Deffontaines (1948) e Sopher (1967), a Geografia da religião tem se tornado um campo de estudo bem-estabelecido, com grupos de investigação, jornais científicos on-line e um crescente número de trabalhos na área. Além disso, Stump (2000) destaca dois fatores que levam os geógrafos a pesquisarem acerca da religião: a importância fundamental da religião como um elemento da cultura; e o distinto caráter geográfico das várias dimensões das crenças e práticas religiosas.

A pesquisadora Lily Kong (2010) afirma que, principalmente a partir do século 21, a Geografia da religião tem se apresentado como um campo fértil para os debates geográficos, em razão do fato de a crescente urbanização, a degradação ambiental e o envelhecimento populacional, por exemplo, criarem contextos em que as dinâmicas religiosas se apresentam como protagonistas da trama geográfica, fazendo com que cada vez mais geógrafos trilhem os caminhos da Geografia da religião. Assim, ela menciona que a atual dinâmica social está fortemente entrelaçada aos fenômenos religiosos e, consequentemente, os estudos sociais parecem abrir um espaço maior para a questão religiosa.

\section{GEOGRAFIA E RELIGIÃO NO CENÁRIO BRASILEIRO ATUAL}

Atualmente os estudos acerca da Geografia da religião no Brasil têm sido desenvolvidos por meio de dois vieses diferentes, representados por dois centros de pesquisa: o Núcleo de Estudos e Pesquisas sobre Espaço e Cultura (Nepec), da Universidade do Estado do Rio de Janeiro (Uerj), liderado por Zeny Rosendahl; e o Núcleo de Estudos em Espaço e Representações (Neer-Curitiba), assim como o Núcleo Paranaense de Pesquisa em Religião (Nupper), ligados à Universidade Federal do Paraná (UFPR) e representados por Sylvio Fausto Gil Filho.

Em uma das edições da Revista Estudos da Religião, Gil Filho (2009) destaca as perspectivas e abordagens da Geografia da religião e afirmar que a "Virada Cultural" e a "Virada Linguística" - movimentos originários da Nova Geografia Cultural" - impulsionaram o ressurgimento dos debates acerca da Geografia da religião, colocado em baila pelos geógrafos brasileiros no início do século 21. Sendo assim, assevera Gil Filho (2009, p. 5) que,

atualmente, algumas tendências são discerníveis na Geografia da Religião: parte dos geógrafos a considera como tema da Geografia Cultural e se concentra nas abordagens geradas no interior da própria disciplina; outros pendem mais para uma autonomia como subdisciplina da Geografia Humana com métodos e abordagens próprias, em um diálogo maior com outras disciplinas que pesquisam o fenômeno religioso.

De acordo com Corrêa e Rosendahl (2010, p. 1), a Nova Geografia Cultural "resgata e amplia as bases epistemológicas desenvolvidas pela geografia cultural de Sauer e dos geógrafos europeus. Amplia também o temário, incluindo em seus estudos a dimensão não-material da cultura". 
As duas tendências da Geografia da religião brasileira são distintas: uma "busca apreender as manifestações espaciais do fenômeno religioso a partir das formas religiosas já impressas na paisagem" e a outra "busca compreender as manifestações religiosas partindo das dimensões estruturantes e do caráter fenomenológico e, posteriormente, das estruturas [...] da religião" (SILVA; GIL FILHO, 2009, p. 76). Os trabalhos Hierópolis: o sagrado e o urbano, de autoria de Zeny Rosendahl (1999), e Espaço sagrado: estudos em Geografia da religião, de autoria de Sylvio Fausto Gil Filho (2008), representam tais perspectivas.

Zeny Rosendahl (1999) entende o sagrado como projeção cultural, atentando para os aspectos visíveis da religião. Desse modo, segundo Frangelli (2010, p. 34), “[...] podemos definir o estudo geográfico da religião [...] como um estudo voltado para a compreensão da manifestação espacial do sagrado". Além disso, Frangelli (2010, p. 34) esclarece que a abordagem proposta por Rosendahl (1999) deve ser compreendida como

uma combinação entre a motivação religiosa na criação, modificação ou destruição de determinados lócus, objetivando satisfazer um impulso religioso em produzir, reproduzir e influenciar simbolicamente certos lócus a fim de cumprir com essa necessidade de união do homem com a sua religiosidade (FRANGELLI, 2010).

Para elaborar a sua abordagem geográfica acerca da religião, Rosendahl (1999) utiliza os conceitos de sagrado e profano - e sua dicotomia - conforme Mircea Eliade (1999). Assim sendo, Rosendahl (1999, p. 231) afirma:

De imediato reconhece-se a dicotomia que existe entre os termos [sagrado e profano]. O sagrado se apresenta absolutamente diferente do profano, isto é, o primeiro relaciona-se a uma divindade e o segundo, não. A palavra sagrado tem o sentido de separação e definição, em manter separadas as experiências envolvendo uma divindade, de outras experiências que não envolvem, consideradas profanas.

Do mesmo modo, conforme Frangelli (2010, p. 34), Zeny Rosendahl interpreta o espaço considerando o fenômeno religioso por meio do destaque da "ação do sagrado":

Rosendahl (1994) identifica que entre os homens existe um conjunto de crenças e práticas que persistem ao longo dos tempos e que possuem uma natureza mística ou religiosa, fortemente atribuída a objetos consagrados e espacialmente delimitados, tanto em sua forma - no sentido de extensão -, como em sua fixação - no sentido de localizados em um lócus. A partir destas observações a pesquisadora procura definir a natureza qualitativa destes lócus diferenciados pela ideia de sagrado e pela sua manifestação no espaço.

O viés teórico, desenvolvido por Rosendahl, atenta, primordialmente, para as formas espaciais da religião, e "nessa abordagem o elemento humano aparece como um fluxo em deslocamento cuja atuação é remetida à influência exercida pela organização topológica do sagrado" (SILVA, 2010, p. 39). Sendo assim, o sujeito tem participação passiva na trama geográfica do fenômeno religioso.

Esse viés teórico é bastante influente no campo da Geografia da religião. Com esse sentido, muitos estudos vêm considerando que os templos, os lugares e as cidades sagradas, bem como os centros de irradiação, influenciam o elemento humano por 
intermédio de suas qualificações e seus deslocamentos. Tem-se, desse modo, estudos que priorizam os aspectos mais objetivos da dinâmica religiosa, deixando-se a subjetividade em segundo plano.

Partindo de lastro fenomenológico, Gil Filho (2007) desenvolve abordagem do fenômeno religioso atentando para os aspectos subjetivos deste, advertindo o risco de nos atermos ao fenômeno apenas pelas suas feições físicoespaciais - aspectos visíveis, concretos -, não nos atendo aos "aspectos mais íntimos e subjetivos":

Torna-se necessário preservar na análise os qualitativos que evidenciam o fenômeno religioso enquanto realidade própria da religião. Visto que em diversas abordagens há uma descaracterização da religião sob os auspícios da objetividade científica. Circunscrever o fenômeno religioso apenas em sua materialidade imediata é descurar seus aspectos mais íntimos e subjetivos. Nossa premissa é que a análise do fenômeno religioso requer uma cognição especial, uma sensibilidade às suas nuanças a fim de captar suas características mais sutis. $O$ fenômeno religioso aparece mais nítido no plano do cotidiano. Não é suficiente que o fenômeno se apresente como matéria-prima da ciência que praticamos, é necessário penetrar nos seus sentidos últimos e compreender o que dizem (p. 212).

Dessa maneira, ele afirma que é pertinente ir além do empirismo prático-religioso, procurando-se compreender os sentidos das práticas religiosas. Tal apontamento causa, por vezes, certo estranhamento/desconforto teórico pela razão de promover um discurso mais abstrato/subjetivo, porém não deve ser negligenciado pelos estudiosos em geografia, pois, buscando-se as características mais sutis que incentivam o sujeito a deixar sua marca no espaço, propõe-se um conhecimento mais autêntico da respectiva fé, aproximando-se o fato religioso de outros fenômenos complexos do seio humano.

Assim, Gil Filho (2007, 2008, 2009) coloca em baila uma orientação teórica que versa pelos aspectos não visíveis da religião, ao mesmo tempo em que destaca a ação do homem na produção de seu espaço, de sua realidade: "presume-se que é pelo espaço de ação do fiel que se pode vislumbrar os espaços da religião, são as representações, as percepções do fiel em face do discurso religioso os estruturantes do fenômeno religioso" (SILVA, 2010, p. 39).

Destarte, constatamos que a religião tem ocupado cada vez mais seu espaço nos estudos geográficos - tanto na escala nacional quanto na internacional -, não se restringindo a apenas uma abordagem, mas utilizando-se de enfoques locacionais, funcionais e práticos para as análises mais profundas do fenômeno religioso. Por isso, Gil Filho (2007, p. 210) afirma que

a Geografia da Religião circunscrita a uma interpretação espacial da prática religiosa ou do conjunto de objetos religiosos da paisagem é limitada. Todavia, em seu sentido amplo, a prática religiosa se apresenta como um fenômeno da cultura humana inspirada na busca da transcendência ou imanência. A materialidade imediata da prática religiosa não é um fim em si mesmo, mas um meio inicial de compreensão da dimensão religiosa. 
Compreendemos, portanto, que a Geografia da religião deve se ater ao fenômeno religioso por meio de abordagens objetivas e subjetivas, o que amplia consideravelmente o entendimento acerca do fenômeno estudado, não se limitando apenas às formas materiais, mas buscando-se compreender o todo que estrutura o fenômeno religioso no processo de produção do espaço.

\section{A PRODUÇÃO DO ESPAÇO POR MEIO DA RELIGIÃO}

Ao pensar sobre o saber religião em geografia, destacamos dois pontos para os quais a perspectiva cultural aponta: o sagrado e o profano. É pertinente entender como o sagrado conforma espaços e como estes se diferenciam dos espaços profanos. $O$ sagrado e o profano opõem-se e, ao mesmo tempo, se complementam, ocorrendo que, à medida que há oposição, há também atração entre eles, pois tudo aquilo que não é sagrado é profano (ROSENDAHL, 1996; ELIADE, 1992). Dessa maneira, diante de determinada sacralidade, existe uma profanidade que a rodeia.

Eliade (1992) assevera que o homem concebe o que é o sagrado a partir de sua hierofania, ou seja, de sua manifestação, o que acaba por gerar uma intrínseca relação - mas também podemos chamar de dualidade - na instauração do sagrado-profano -, organizando o cosmo de uma dada realidade. Assim sendo, "o sagrado manifesta-se sempre como uma realidade inteiramente diferente das realidades "naturais" (ELIADE, 1992, p. 16).

Tais hierofanias - manifestações do sagrado - podem ocorrer por meio de um objeto - um templo, uma árvore ou até mesmo uma pessoa - estruturando a vida do homem pelas sacralidades que ele atribui a um determinado ser, passando a concebê-lo como sagrado. Com esse pensamento, Eliade (1992, p. 26) salienta que,

quando o sagrado se manifesta por uma hierofania qualquer, não só há rotura na homogeneidade do espaço, como também revelação de uma realidade absoluta, que se opõe à não-realidade da imensa extensão envolvente. A manifestação do sagrado funda ontologicamente o mundo.

Referenciando os estudos acerca da religião produzidos por Durkheim (1912), Berger (1985) e Weber (1964), Rosendahl (1997) destaca que o sagrado organiza a manifestação espacial, tornando-se, assim, autônomo, ou seja, "o sagrado se manifesta sob a forma de hierofania no espaço [...], revela-se como um dom carismático que o objeto ou a pessoa possui [...] e se impõe por ele mesmo [...]" (ROSENDAHL, 1997, p. 121). Desse modo, ressalta que "o espaço sagrado é o lócus de uma hierofania, isto é, uma manifestação do sagrado, a qual permite que se defina um ponto fixo, ponto de toda a orientação inicial, o centro do mundo" (ROSENDAHL, 1997, p. 121).

Continuando essa discussão, a autora afirma que a dinâmica espacial religiosa é sugerida pela dicotomia sagrado-profano, o que propõe uma estruturação específica do espaço sagrado. Tais estruturações são reveladas, primordialmente, pelas funções das formas espaciais, na medida em que 
é possível distinguir dois elementos fundamentais no espaço sagrado: o ponto fixo e o seu entorno. No primeiro, as formas espaciais existentes cumprem funções que estão diretamente associadas à hierofania materializada no objeto impregnado do sagrado. $O$ entorno possui os elementos necessários ao crente para a realização de suas práticas e de seu roteiro devocional (ROSENDAHL, 1997, p. 122).

Com essa visão, Rosendahl (1997, p. 122) apresenta sua definição de espaço sagrado:

define-se o espaço sagrado como um campo de forças e de valores que eleva o homem religioso acima de si mesmo, que o transporta para um meio distinto daquele no qual transcorre sua existência. É por meio dos símbolos, dos mitos e dos ritos que o sagrado exerce sua função de mediação entre o homem e a divindade. E é o espaço sagrado, enquanto expressão do sagrado, que possibilita ao homem entrar em contato com a realidade transcendente chamada deuses nas religiões politeístas e Deus nas monoteístas.

Dessa maneira, podemos afirmar que para a autora o espaço seria representado por mediação física, denotada por uma empiricidade detentora de "forças e valores", marcado, especialmente, por uma simbologia que o envolve.

Além disso, Rosendahl (1997, p. 124) enfatiza sobre a atuação do sagrado no espaço que, "através da segregação que o sagrado impõe à organização espacial [...], é possível identificar o espaço profano diretamente vinculado ao sagrado, o espaço profano indiretamente vinculado e o espaço profano remotamente vinculado ao sagrado".

Do mesmo modo, ela afirma que o espaço sagrado pode ser revelado por intermédio de rituais, com o homo religiosus experimentando representações de suas formas espaciais (materiais) que manifestam o sagrado. Assim,

o espaço sagrado se revela não somente através de uma hierofania, mas também por rituais de construção, e, neste caso, os rituais representam repetições de hierofanias primordiais conhecidas. Assim, o espaço sagrado é uma produção intelectual. Sofisticadamente ou não, o homem organiza as forças da sociedade e da natureza. A construção do espaço sagrado, no tempo sagrado, satisfaz as necessidades intelectuais e psicológicas. A manifestação do sagrado é uma realidade que se exprime sob as formas simbólicas que se desenvolvem e se relacionam no espaço e no tempo (ROSENDAHL, 1997, p. 125).

Fica evidente que, para Rosendahl (1997), o sagrado marca de maneira expressiva o espaço, sendo interpretado por meio de manifestações humanas, visão empiricista e estrutura teórica acerca do tema religião estudado historicamente. Sem dúvida, é o entendimento eliadiano que marca primordialmente as discussões propostas por Rosendahl acerca do sagrado e das suas manifestações, conformando-se, desse modo, espaços ditos sagrados. Neste lastro teórico-metodológico, Rosendahl (1997, p. 149) destaca que

o geógrafo quando estabelece como objeto central de sua análise a religião, encara-a sob a dimensão espacial. E para realizar sua pesquisa reconstrói teoricamente o papel do sagrado na recriação do espaço, reconhecendo o sagrado não como 
simples aspecto da paisagem, mas como elemento de produção do espaço. E talvez seja nas hierópolis que, mais nitidamente, o sagrado esteja materializado através de formas espaciais.

Por intermédio da relação dicotômica sagrado-profano, o espaço sagrado é marcado por prerrogativas que são capazes de reorganizar seu entorno e fornecer uma mediação intrínseca entre o fiel e a divindade. Assim, a manifestação do sagrado permite uma esquematização físico-espacial, conforme mostrado na Figura 1. Desse modo, Rosendahl (1997, p. 150) assinala que,

pela segregação que o sagrado impõe à organização espacial, é permitido identificar quatro áreas de atuação do grupo religioso, quatro áreas de intensidade diferenciada da manifestação do sagrado no espaço. São elas: o espaço sagrado, o espaço profano diretamente vinculado ao sagrado, o espaço profano indiretamente vinculado e, por último, o espaço [profano] remotamente vinculado ao sagrado.

Figura 1 - Esquematização do espaço sagrado e do espaço profano
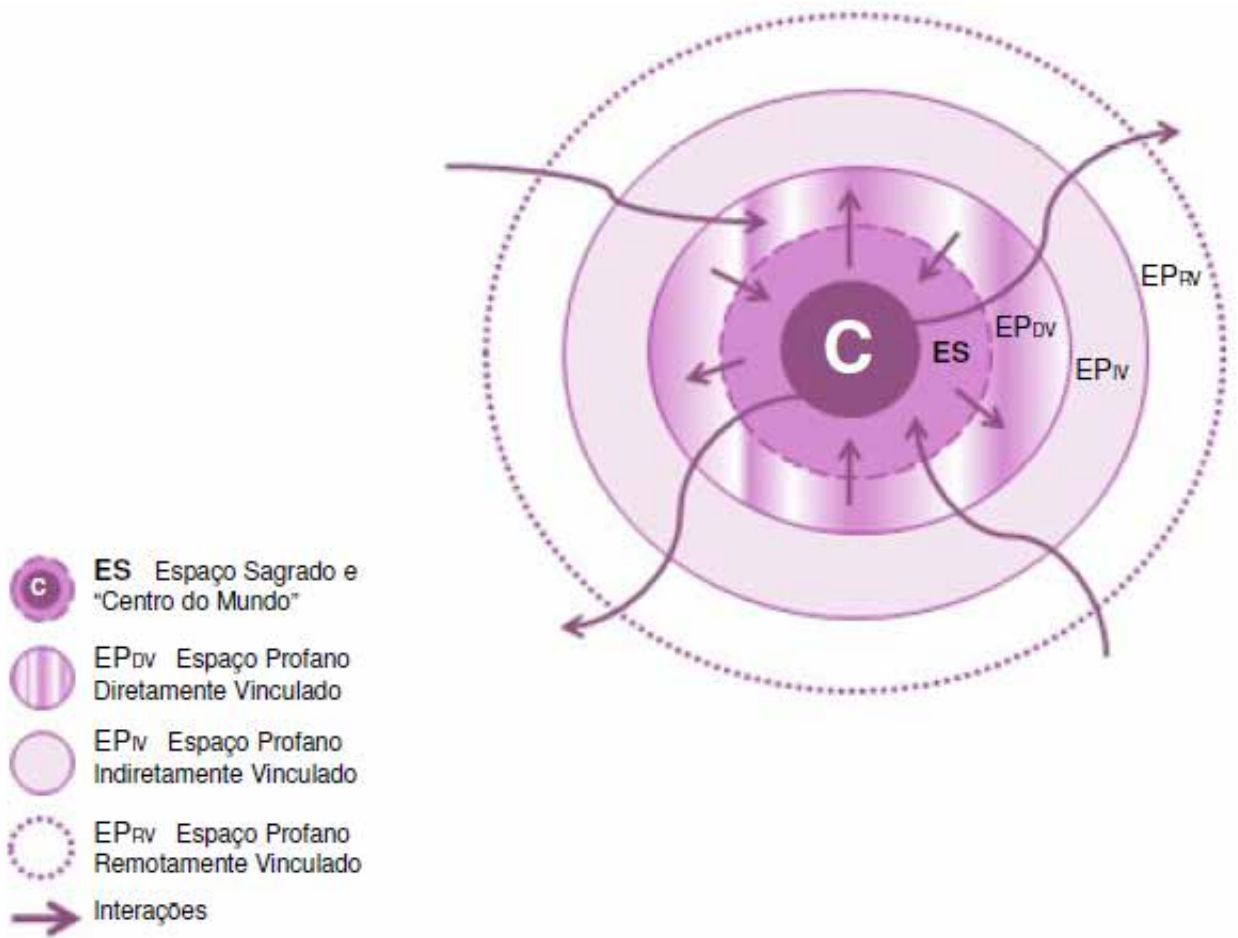

Fonte: ROSENDAHL (1997, p. 123).

As discussões realizadas por Rosendahl concebem o espaço sagrado na dinâmica da manifestação locacional do sagrado, de acordo com hierofanias. Assim, as manifestações espaciais da religião partem das evidências materiais expressas na paisagem, como a instituição de uma igreja ou os espaços sagrados de peregrinação; uma abordagem de base material.

Outro importante autor da geografia, Roberto Lobato Corrêa (2002, p. 129), entretanto, afirma que "se faz necessário dar continuidade a esta perspectiva, aprofundando, porém, a análise das dimensões econômica, política e cultural do lugar que relacionam o sagrado e o profano à sociedade e ao espaço". 
Dando atenção, inicialmente, à dimensão econômica, Corrêa (2002) propõe uma visão da relação entre a produção de bens simbólicos, mercados e redes. Os bens simbólicos são produzidos pelos simpatizantes de cada religião e, à medida que tais adeptos atribuem sentido sagrado (valor sacro) a tais bens, estes são transformados em mercadorias/produtos de valor religioso, portanto, simbólicos.

Segundo Corrêa (2002, p. 130), “[...] é o bem simbólico que dá sentido e significado às práticas religiosas de diferentes grupos". A compreensão do campo simbólico acontece pelo fato de os indivíduos sentirem a necessidade de defender e manifestar seus interesses por meio de bens materiais, fazendo surgir a ideia de capital religioso expresso na demanda e oferta religiosa que "alguns" se empenham em produzir, sendo isto, inclusive, o que muitos denominam de mercado da fé. Assim,

o capital religioso tende a ser acumulado e concentrado nas mãos de um grupo de administradores do sagrado. A separação simbólica entre o saber sagrado e a ignorância profana é reforçada e acentua a distinção entre os produtores do sagrado e os consumidores dos bens simbólicos. O mercado de bens simbólicos a partir da divisão do trabalho se dá por um grupo de trabalhadores especialistas em religião, dotados como porta-vozes do sagrado, investidos de poder institucionalizado ou não, incumbidos da gestão dos bens de salvação, é entendida como um corpo de funcionários do culto, dotados de uma formação especializada em religião, incumbidos da gestão dos bens de salvação e com função específica de satisfazer os interesses religiosos (CORRÊA, 2002, p. 133).

No Brasil, por exemplo, é pertinente citar o fato de o catolicismo promover a produção de um amplo conjunto de bens simbólicos, tais como imagens, terços, livros, medalhas e outros produtos que caracterizam um vasto mercado. Orientado para o crescente consumo por devotos e simpatizantes, atualmente tem-se o mercado da música, seja ela de cunho católico ou protestante, pela venda de CD e DVD ou pelo número de acessos que uma dada música tem no YouTube.

Vale ressaltar, também, que a experiência religiosa é, ao mesmo tempo, individual e coletiva, com sentido único para cada devoto. Destarte, a fé vai ser individualmente vivenciada e coletivamente experimentada por intermédio de crenças e ações simbólicas comunitárias. Assim sendo, quando se diz que um homem é religioso, se quer dizer que este, pela sua fé e experiências vividas, permite uma leitura do espaço que conforma o sagrado e o denota na constituição de territórios religiosos.

Com esse sentido, Corrêa (2002, p. 168) sublinha que

a dimensão política do sagrado permite reconhecer as múltiplas estratégias espaciais existentes entre religião e espaço. $O$ estudo da territorialidade tem significado tanto para as sociedades modernas quanto para aquelas que permanecem tradicionais. $O$ espaço assume uma dimensão simbólica e cultural onde se enraízam seus valores e através do qual se afirma a sua identidade. Ao mesmo tempo, as estratégias espaciais acentuam o domínio político de grupos nacionais que possuem autoridade quase-religiosa. Divisões territoriais e organização hierárquica de religiões institucionalizadas são estratégias políticas adotadas com o objetivo de assegurar o controle, a vivência e a vigilância dos fiéis frente à crescente mobilidade dos homens e a fatos históricos relevantes. Territorialidade religiosa significa o conjunto de práticas desenvolvido por instituições ou grupos no sentido de 
controlar um dado território. Sendo assim, a territorialidade engloba ao mesmo tempo as relações que o grupo mantém com o lugar sagrado (fixo) e os itinerários que constituem o seu território. [Assim], a territorialidade é uma oscilação contínua entre o fixo e o móvel entre, de um lado o território que dá segurança, símbolo de identidade, e, de outro, o espaço que se abre para a liberdade, às vezes também para a alienação. A sacralização de normas, valores e ideias que simbolizam o poder político deve ser celebrada no espaço, é a chamada religião civil, que visa um controle social.

Esta citação reforça o fato de que a ideia de sagrado - atribuída aos lugares, objetos, pessoas, etc. - influencia diretamente na maneira de fazer cultura de um povo. Fundamentados em seus ideais religiosos, as pessoas produzem e organizam o seu espaço a fim de demonstrar o poder de controle de um dado território, muitas vezes sob a influência de uma dada religião.

Dessa maneira, não para encerrar a discussão sobre o estudo da religião na geografia, mas para ressaltar o entendimento de Corrêa (2002), salientamos que o caráter do espaço da religião é calcado nas prerrogativas das noções de sagrado e de profano, e que tais dimensões são manifestadas no espaço e no tempo e, na atualidade, isso é cada vez mais perceptível com o desenvolvimento dos meios de comunicação em massa. Assim, Corrêa (2002, p. 137) esclarece que "espaço, cultura e religião estão reunidos em novos planos de percepção teórica que introduzem uma possibilidade de pensar o sagrado e o profano na ciência. O elo entre espaço e religião fornece material rico à reflexão".

\section{CONSIDERAÇÕES FINAIS}

As relações entre Geografia e religião são evidentes e, desse modo, as reflexões e análises sobre o saber religião em geografia devem ser mais trabalhadas pelos geógrafos e professores de geografia.

A religião tem a peculiaridade de plasmar o espaço geográfico de modo específico, por meio de aspectos culturais, de relações de poder e de aspectos simbólicos e propriamente religiosos. Destarte, quando a geografia se debruça sobre o fenômeno religioso, ela o explica por intermédio das categorias de análise e das dimensões do espaço geográfico, considerando-se a religião um fenômeno espacialmente colocado.

Além disso, é pertinente frisarmos que o pensamento geográfico acerca da religião apresenta uma diversidade temática, metodológica e teórica, fato que possibilita a realização de estudos interdisciplinares e coerentes com o espaço geográfico enquanto objeto de estudo da geografia.

Em suma, sublinhamos a importância de se trabalhar o saber religião em geografia, tendo-se em vista que a religião e a geografia têm relações intrínsecas, sendo viável a análise da produção do espaço geográfico conforme questões ou aspectos religiosos. 


\section{REFERÊNCIAS}

ANDRADE, C. Geografia bíblica. 17. ed. Rio de Janeiro: CPAD, 2006.

BERGER, P. O dossel sagrado: elementos para uma teoria sociológica da religião. São Paulo: Editora Paulinas, 1985.

BUTTIMER, A. Grasping the dynamism of the lifeworld. Annals of the Association of American Geographers, v. 66, n. 2, 1976.

BÜTTNER, M. The significance of the reformation for the reorientation of Geography in Lutheran Germany. History of Science, v. 17, 1979.

BÜTTNER, M. El significado de la reforma para la nueva orientación de la geografía en la Alemania Luterana. Geocrítica, Universidad de Barcelona, a. III, n. 12, 22, 1987. Disponível em: http://www.ub.es/geocrit/ geo12.htm. Acesso em: 10 fev. 2019.

CLAVAL, P. As abordagens da geografia cultural. In: CASTRO, I. E. et al. (org.). Explorações geográficas: percursos no fim do século. Rio de Janeiro: Bertrand Brasil, 1997.

CORRÊA, R. L. A geografia cultural francesa: apresentando textos selecionados. In: CORRÊA, R. L.; ROSENDAHL, Z. Geografia cultural: um século. Rio de Janeiro: Eduerj, 2002.

CORRÊA, R. L.; ROSENDAHL, Z. Introdução à geografia cultural. 3. ed. Rio de Janeiro: Bertrand Brasil, 2010. DEFFONTAINES, P. Geographie et religions. Paris: Gallimard, 1948.

DURKHEIM, E. As formas elementares da vida religiosa. São Paulo: Martins Fontes, [1912] 1996.

ELIADE, M. O sagrado e o profano: a essência das religiões. Tradução Rogério Fernandes. São Paulo: Martins Fontes, 1992.

FICKELER, P. Questões fundamentais na geografia da religião. Espaço e Cultura, Edição Comemorativa, p. 7-35, [1947] 2008.

FRANGELLI, P. Estudando um subcampo intelectual acadêmico: a geografia da religião no Brasil - 19892009. 2010. Dissertação (Mestrado em Geografia) - Universidade do Estado do Rio de Janeiro, Rio de Janeiro, 2010.

GIL FILHO, S. F. Geografia da religião: reconstruções teóricas sob o idealismo crítico. In: KOZEL, S.; SILVA, J. C.; GIL FILHO, S. F. (org.). Da percepção e cognição à representação: reconstruções teóricas da Geografia cultural e humanista. São Paulo: Terceira Imagem; Curitiba: NEER, 2007. p. 190-220.

GIL FILHO, S. F. Espaço sagrado: estudos em geografia da religião. Curitiba: Editora Ibpex, 2008.

GIL FILHO, S. F. Da ontologia do sagrado de Rudolf Otto ao sagrado como forma simbólica. In: JUNQUEIRA, S. (org.). O sagrado: fundamentos e conteúdo do ensino religioso. Curitiba: Ibpex, 2009. p. 1-35.

KONG, L. Geography and religion: trends and prospects. Progress in Human Geography, v. 14, n. 3, p. 355$371,1990$.

KONG, L. Global shifts, theoretical shifts: changing geographies of religion. Progress in Human Geography, v. 34, n. 6, p. 755-776, 2010.

MONEY, N. K. Geografia histórica do mundo bíblico. 12. ed. São Paulo: Editora Vida, 2002.

PARK, C. Sacred worlds: an introduction to Geography and religion. Londres: Routledge, 1994.

PARK, C. Religion and Geography. In: HINNELS, J. (ed.). Routledge companion to the study of religion. London: Routledge, 2004.

RONIS, O. Geografia bíblica: contribuição para o estudo de Geografia histórica das terras bíblicas. Rio de Janeiro: Juerp, 1994.

ROSENDAHL, Z. Espaço e religião: uma abordagem geográfica. Rio de Janeiro: Eduerj; Nepec, 1996.

ROSENDAHL, Z. O sagrado e o espaço. In: CASTRO, I. E.; GOMES, P. C. C.; CORRÊA, R. L. (org.). Explorações geográficas: percursos no fim do século. Rio de Janeiro: Bertrand Brasil, 1997.

ROSENDAHL, Z. Hierópolis: o sagrado e o urbano. Rio de Janeiro: Eduerj, 1999.

ROSENDAHL, Z.; CORRÊA, R. L. (org.). Manifetações da cultura no espaço. Rio de Janeiro: Eduerj, 1999.

SILVA, A. S.; GIL FILHO, S. F. Geografia da religião a partir das formas simbólicas em Ernst Cassirer: um estudo da Igreja Internacional da Graça de Deus no Brasil. Rever - Revista de Estudos da Religião, v. 9, p. 73-91, 2009.

SILVA, A. S. Religião \& espacialização: o caso da Igreja Internacional da Graça de Deus. 2010. Dissertação (Mestrado em Geografia) - Universidade Federal do Paraná, Curitiba, 2010.

SOPHER, D. E. Geography of religions. Englewood Cliffs: Prentice Hall, 1967. 
STADELBAUER, J. Espaço e linguagem no foco das ciências geográficas. In: AUER, P.; SZMRECSANYI, B. Linguagem, espaço e geografia. WORKSHOP, 3. Anais [...]. Freiburg: Instituto de Freiburg de Estudos Avançados, 2009. p. 1-45.

STUMP, R. W. The Geography of religion: faith, place, and space. Lanham: Rowman and Littlefield Publishers, 2000.

TUAN, Yi-Fu. Geografia humanística. In: CHRISTOFOLETTI, A. (org.). Perspectivas da geografia. São Paulo: Difel, 1982. p. 143-164.

USARSKI, F. O espectro disciplinar da ciência da religião. São Paulo: Paulinas, 2007.

WEBER, M. Economía y sociedad. Buenos Aires: Fondo de Cultura Económica, 1964. 